\title{
Drug Prescription Patterns in Osteoarthritis Patients in a Tertiary Care Hospital in China
}

FEI WANG, YIJUN WANG ${ }^{1}$, HUANI XING² , LIMIN XU, JIPING ZHOU*

Department of Limb Trauma, ${ }^{1}$ Department of Orthopedics, ${ }^{2}$ Department of Function, Wendeng Hospital of Traditional Chinese Orthopedics and Traumatology of Shandong Province, Wendeng, Shandong Province, 264400, China

Wang et al.: Drug Utilization Patterns for Osteoarthritis in a Chinese Province

The study was conducted to evaluate the prescription patterns of various agents for osteoarthritis in a population specific cohort in Shandong Province, China. Data obtained from the Hospital Databases, which consisted of electronic medical records and prescription information. All the enrolled study subjects ( $n=212$ 546) are with a clinically detected osteoarthritis during 2010-2015. Medicine prescription pattern was demonstrated using medication possession ratio, corresponding number of days administered with that particular medicine. The drugs examined comprised of analgesics (metamizole and paracetamol), oral and topical non-steroidal antiinflammatory drugs, cyclooxygenase-2 inhibitors, opioids (fentanyl and tramadol) and symptomatic slow-acting drugs in osteoarthritis. The most generally employed regimen for 
the treatment osteoarthritis was consisted of mainly three agents (53.5\% osteoarthritis patients). Most regularly used medicines (medication possession ratio $\geq 50 \%)$ were chondroitin $(21 \%)$, glucosamine $(16 \%)$ and oral non-steroidal antiinflammatory drugs $(14 \%)$. Use of chondroitin, cyclooxygenase 2 inhibitors and opioids was increased beyond 5 years of tenure. However, frequency of all the other drugs was decreased. The combination regimens could cause potential drug interactions, may impact the health of osteoarthritis patients. In this study, increase in the use of cyclooxygenase 2 inhibitors and opioids is substantial due to the effect on safety and prices of the medication. Findings of this study should alert clinicians to the potential unnecessary costs and iatrogenic effects in the management of patients with osteoarthritis.

\section{Key words: Osteoarthritis, drug utilization pattern, chondroitin, glucosamine, NSAIDs}

Osteoarthritis (OA) can significantly influence a patient's quality of life and daily functioning, which in turn affects the productivity. Moreover, it may impact on the healthcare costs too, with present forecasting, OA could be the fourth largest reason for the disability by the year $2020^{[1]}$. A latest epidemiological report regarding the healthcare burden of 291 different health anomalies, keeps OA among major 25 reasons with the highest influence on health worldwide ${ }^{[2]}$. China is a large country, with a population of 1.3 billion. In $2010,25.3 \%$ of the population comprised of age group $\geq 50 \mathrm{y}$, who are very much prone to get affected with OA. To date, data regarding the precise estimates of prevalence of OA in Chinese population is lacking. However, a recent study from China comprising of 17128 individuals, reported $8.1 \%$ symptomatic knee $\mathrm{OA}^{[3]}$.

OA was proved to be the cause of raised morbidity, with a robust link with metabolic syndrome, diabetes and walking anomaly ${ }^{[4]}$. A latest study demonstrated an amplified risk of mortality (especially of cardiovascular anomalies) in the OA patients ${ }^{[5]}$. In addition, surgery in OA patients for joint replacement shows a great economic burden. Indeed, according to the UK-based registry, among all hip/knee joint related surgeries around $90-95 \%$ cases were ascribable to $\mathrm{OA}^{[6]}$.

Presently there are ample gaps in the current literature to address the drug utilization practices among the Chinese OA patients. Numerous therapeutic options are available in the market to deal with OA-linked symptoms, however presently there is no unique practicing strategy. There is a need to have a consensus on the various therapeutic modalities to afford better healthcare for OA patients, with usage of first-line drugs. The diversity in treatment of OA with various medications led to new consequences for safety and healthcare cost concerns ${ }^{[7]}$. Among these medicines, several were linked with augmented cardiovascular incidents in OA population ${ }^{[5]}$. Several other factors such as limitations of the current medications and need for the expedite recuperation current studies are required.

In this study, the objective was to ascertain the utility patterns of various drugs and their combinations for $\mathrm{OA}$ in a geographically chosen population-based group of OA patient pool in Wendeng, Shandong Province, China. Moreover, one of the emphases was on cardiovascular risk factors among OA patients. Lastly, in this study the utility of each therapeutic agent among freshly detected OA patients in the initial year was examined.

The data are acquired from Wendeng, Shandong Province, electronic database. It consists of health records of OA patients who were registered in one of the 212 health care centers, which participated in this study. The database covers a population of two million OA patients and an overall 2801 participating general practitioners. The electronic database comprised of the clinical and referral incidents recorded in the primary health centers ${ }^{[8,9]}$. Healthcare community collects the data (comprehensive demographic features, prescription documents, and diagnostic laboratory test findings) using ICD 10 codes for various symptoms and comorbidities and properly prepared sheets for collecting the clinical and administrative data, such as country of birth, sex, age, height, weight, smoking and drinking habits ${ }^{[8,9]}$. Encryption of personal and clinical information guarantees the concealment of the data in the electronic database. The data is completely

This is an open access article distributed under the terms of the Creative Commons Attribution-NonCommercial-ShareAlike 3.0 License, which allows others to remix, tweak, and build upon the work non-commercially, as long as the author is credited and the new creations are licensed under the identical terms

Accepted 21 March 2019

Revised 14 November 2018

Received 17 August 2018

Indian J Pharm Sci 2019;81(3):555-561 
interconnected to authorized dispensary (Pharmacy, Wendeng Hospital of Traditional Chinese Orthopedics and Traumatology of Shandong Province), which is the source for the current study data.

This study considered subjects aged above $40 \mathrm{y}$ as of 1 January $2010(n=212546)$. In the study tenure (2010-15), subjects of various types of OA, such as polyarticular, hand, hip, knee, spine and unspecific OA. Subjects with a previous history of inflammatory allied arthritis were not included.

All the study subjects were segregated at baseline (date diagnosing OA) age, sex, joints affected and BMI. Drug utilization data were acquired from the authorized dispensary invoices sources database further segregated by employing Anatomical Therapeutic Chemical (ATC) system $^{[10]}$. The types of agents utilized were oral nonsteroidal antiinflammatory drugs (NSAIDs), topical NSAIDs, paracetamol alone or in combination, cyclooxygenase (COX)-2 enzyme inhibitors, the 3-symptomatic slow-acting drugs (SSADs) in OA, other generally employed non-narcotic analgesics (metamizole) and the most generally utilized narcotic analgesics (tramadol and fentanyl).

The medications usage pattern was demonstrated in the data points such as present incidence of use, incidences in the new cases use and overall amount of utility. A combination of medications was defined as the concurrent utility of more than one in the same calendar year. Prevalent case was defined, a patient who was frequent user of a specific drug if the patient filled at least one prescription for that drug at any point of time during the tenure. The denominator of prevalence values was considered both prevalent and incident $\mathrm{OA}$ patients.

Overall extent of utilization of each medication was showed in as medication possession ratios (MPRs). The MPR is a standard measure, which can be termed as the total number of days for which a drug was taken divided by the total number of days of treatment ${ }^{[11]}$. Frequent utility of a certain medication was termed as an $\mathrm{MPR}=50 \%$ and occasional use as an MPR $=25 \%$.

The annual occurrence of employing a particular drug during 2010-15, a patient was termed as a new user of a medication if that patient started employing the drug in the first year after OA diagnosis, having filled no prescriptions for the same medication in the previous year. Therefore, the denominator of occurrence measured included only subjects with an incident diagnosis of OA in the index year.

May-June 2019

Indian Journal of Pharmaceutical Sciences
The quantity and the rate of using each drug and their combinations were investigated in this study (in both already existing and freshly diagnosed OA cases). During the initial days, features of each drug user groups were captured employing descriptive statistical methods. The work was done in line with the highest ethical principles specified in the Declarations of Helsinki. Present study was permitted by Ethics Committee of Wendeng Hospital of Traditional Chinese Orthopedics and Traumatology of Shandong Province. Coding of individuals was done to warrant the confidentiality of data.

During the 5-y tenure of the study, around 212546 subjects were diagnosed with OA and encompassed in the analyses of this study. The study population was having an average age of 65.48+8.10y and 74391 (34.9 $\%)$ were males. Among these subjects, around 62764 (38.7\%; BMI presented) were overweight and 67091 $(41.5 \%)$ were obese during the time of OA detection. In this study, frequently affected joints in subjects diagnosed OA were the knee ( $\mathrm{n}=86$ 018, $40.4 \%)$, followed by polyarticular/multiple joints $(n=37266$, $17.5 \%)$, hand $(\mathrm{n}=32381,15.2 \%)$ and spine $(\mathrm{n}=29$ $756,13.9 \%$ ). Patient characteristic features are shown in Table 1.

Frequently prescribed agents among different types of medications were NSAIDs ( $\mathrm{n}=164566,77.4 \%$ ), paracetamol (alone or in combination, $(n=154421$, $72.6 \%)$, chondroitin $(\mathrm{n}=37142,17.4 \%)$, glucosamine $(\mathrm{n}=24283,11.4 \%)$, tramadol $(\mathrm{n}=31954,15.0 \%)$ and COX-2 enzyme inhibitors ( $\mathrm{n}=25 \mathrm{016}, 11.7 \%$ ). Younger people frequently used SSADs in OA, whereas in elderly people, tramadol was most frequently used. SSADs usage was very frequent in hand and knee OA; whereas tramadol usage was very frequent in polyarticular and hip OA. Overall, tramadol usage was most common in all OA patients who were suffering with all the comorbidities. Incidentally, cardiovascular risk factors were very frequent (30\% had hypertension and $>10 \%$ had type 2 diabetes in our observations) in the OA patients who employed COX-2 enzyme inhibitors and NSAIDs, with an incidence of more than $50 \%$ and $17 \%$ for type 2-diabetes and hypertension, correspondently.

The frequencies of using various medications in this study are described in Table 2. Among the patients, about half of the patients used at least 3 agents per year $(\mathrm{n}=113675,53.5 \%)$, whereas only a limited patients used one of the agents $(n=34766,14.6 \%)$ or 
TABLE 1: DEMOGRAPHIC FEATURES OF PATIENTS AT THE TIME OF OSTEOARTHRITIS DETECTION

\begin{tabular}{lc}
\hline Demographic feature & Frequency \\
\hline Sample size, $\mathrm{n}$ & 212546 \\
Age (mean $\pm \mathrm{SD}$ ) years & $65.48 \pm 8.10$ \\
Gender (males), $\mathrm{n}(\%)$ & $74391(34.9)$ \\
BMI $\left(\mathrm{kg} / \mathrm{m}^{2}\right)$ & \\
Underweight $(\mathrm{mean} \pm \mathrm{SD})$ & $870 \pm 0.4$ \\
Normal (mean $\pm \mathrm{SD})$ & $30881 \pm 14.5$ \\
Overweight $(\mathrm{mean} \pm \mathrm{SD})$ & $62764 \pm 29.5$ \\
Obese (mean $\pm \mathrm{SD})$ & $67091 \pm 31.5$ \\
No data $($ mean $\pm \mathrm{SD})$ & $50940 \pm 23.9 ;$ with data 161606 \\
Joint $(\mathrm{s})$ affected, $\mathrm{n}(\%)$ & \\
Knee & $86018(40.4)$ \\
Polyarticular & $37266(17.5)$ \\
Hand & $32381(15.2)$ \\
Spine & $29756(13.9)$ \\
Hip & $27125(12.7)$ \\
\hline SD: Standard deviation; BMl: body mass index; underweight: BMl \\
$<18.5 \mathrm{~kg} / \mathrm{m}^{2} ;$ normal weight: BMI 18.5 to $<25 \mathrm{~kg} / \mathrm{m}^{2} ;$ overweight: \\
BMl 25 to $<30 \mathrm{~kg} / \mathrm{m}^{2} ;$ and obesity: BMI $\geq 30 \mathrm{~kg} / \mathrm{m}^{2}$
\end{tabular}

no agent ( $\mathrm{n}=14487,6.8 \%$ ) of the total drugs studied. Frequently used combined drug regimens are topical NSAIDs+analgesics, oral NSAIDs+analgesics and SSADs + oral NSAIDs.

The magnitude of medications usage is displayed in Table 3. The medication consumers are defined as regular $(\mathrm{MPR}=50 \%)$ and irregular type $(\mathrm{MPR}=$ $25 \%$ ). Frequent medication consumers were observed with chondroitin $(21.0 \%)$, after that glucosamine $(16.0 \%)$ and NSAIDs $(14.0 \%)$. On the contrary, very low numbers of regular medication consumers were found with metamizole $(0.9 \%)$, paracetamol in combination with tramadol $(1.2 \%)$ or other drugs $(0.4 \%)$ and fentanyl $(0.2 \%)$.

This study showed that among the several agents, NSAIDs $(\sim 80 \%)$ and paracetamol $(\sim 75 \%)$ were frequently employed in the population of this study. Opioid drugs such as fentanyl and tramadol were

TABLE 2: PRESCRIBING PATTERN OF VARIOUS DRUGS AND COMBINATIONS IN PATIENTS DIAGNOSED WITH OSTEOARTHRIS

\begin{tabular}{lcccc}
\hline Drug/combination & & $\mathrm{n}$ & $\%$ & $\mathbf{9 9} \% \mathrm{Cl}$ (LL, UL) \\
\hline More than three ( $\geq 3)$ & Three or more drugs & 113675 & 53.5 & $43.6,44.2$ \\
& Oral NSAIDs+analgesics & 29456 & 13.9 & $13.1,12.5$ \\
& Topical NSAIDs+analgesics & 6276 & 3.0 & $3.8,2.1$ \\
Two (2) & SSADs+oral NSAIDs & 4250 & 2.0 & $3.0,3.2$ \\
& Oral+topical NSAIDs & 6776 & 3.2 & $2.2,2.5$ \\
& SSADs+analgesics & 2125 & 1.0 & $0.9,1.7$ \\
& Oral NSAIDs & 15640 & 7.4 & $7.1,6.4$ \\
& Other analgesics & 13177 & 6.2 & $6.5,6.7$ \\
One (1) & SSADs & 3081 & 1.4 & $1.2,1.5$ \\
& Topical NSAIDs & 1702 & 0.8 & $0.7,0.9$ \\
& Opioids & 1062 & 0.5 & $0.3,0.5$ \\
0 & Cyclooxygenase-2 inhibitors & 839 & 0.4 & $0.1,0.3$ \\
& No drugs & 14487 & 6.8 & $6.8,5.2$ \\
\hline
\end{tabular}

NSAIDs: Non-steroidal anti-inflammatory drugs; SSADs: symptomatic slow-acting drug in OA, $(\mathrm{n}=212$ 546)

TABLE 3: DESCRIPTION OF INDIVIDUALS WITH MPR DEFINED AS REGULAR AND OCCASIONAL USERS

\begin{tabular}{|c|c|c|c|c|c|c|c|}
\hline \multirow{2}{*}{ Medication } & \multirow{2}{*}{$\begin{array}{c}\text { Any use } \\
\mathrm{n}\end{array}$} & \multicolumn{3}{|c|}{ Regular users (MPR $\geq 50 \%$ ) } & \multicolumn{3}{|c|}{ Occasional users (MPR $\geq 25 \%)$} \\
\hline & & $\mathrm{n}$ & $\%$ & $95 \% \mathrm{Cl}(\mathrm{LL}, \mathrm{UL})$ & $\mathrm{n}$ & $\%$ & $95 \% \mathrm{Cl}(\mathrm{LL}, \mathrm{UL})$ \\
\hline Oral NSAID & 164566 & 23039 & 14 & $13.9,13.64$ & 46902 & 28.5 & $29.2,28.8$ \\
\hline Paracetamol & 154421 & 16456 & 10.7 & $9.0,11.1$ & 40619 & 26.3 & $24.18,24.5$ \\
\hline Metamizole & 52052 & 480 & 0.9 & $0.7,0.8$ & 1181 & 2.3 & $2.7,2.2$ \\
\hline Chondroitin & 37142 & 7799 & 21 & $19.6,19.8$ & 14462 & 38.9 & $37.2,39.4$ \\
\hline Tramadol+paracetamol & 31954 & 380 & 1.2 & $0.8,0.7$ & 818 & 2.6 & $2.4,2.1$ \\
\hline Tramadol & 27453 & 1647 & 6 & $6.1,56.9$ & 3814 & 13.9 & $11.9,12.9$ \\
\hline COX-2 inhibitor & 25016 & 3001 & 12 & $10.9,11.8$ & 5857 & 23.4 & $20.9,22.8$ \\
\hline Glucosamine & 24283 & 3885 & 16 & $16.2,15.9$ & 7405 & 30.5 & $29.1,32.7$ \\
\hline $\begin{array}{l}\text { Paracetamol } \\
\text { combinations }\end{array}$ & 19656 & 75 & 0.4 & $0.2,0.4$ & 184 & 0.9 & $0.8,1.2$ \\
\hline Diacerein & 8832 & 983 & 11.1 & $10.8,11.4$ & 1816 & 20.6 & $18.9,20.4$ \\
\hline Fentanyl & 8751 & 18 & 0.2 & $0.1,0.35$ & 35 & 0.4 & $0.29,0.6$ \\
\hline
\end{tabular}

COX-2: Cyclo-oxygenase 2; MPR: medication possession ratio 
frequently prescribed drugs in poly-articular and hip OA patients. Whereas, SSADs utility was highly frequent in younger age group patients, mainly in the patients of knee and hand OA.

This study showed that prescription pattern and usage of various medicines in the subjects who were clinically detected with OA in a 5-y tenure in Wendeng, Shandong Province, China. This study witnessed about $80 \%$ using 2 or more drugs and more than $50 \%$ patients used at least 3 drugs concurrently. NSAIDs and analgesics were the frequently employed first line medications, with oral NSAIDs and analgesics being the generally used add on secondary medication and opioids being the frequently used third-level therapy. The degree of using these medications appears to be very low with all these agents, with more than $98 \%$ of metamizole and opioid users having low drug use ( $<25 \%$ MPR). NSAIDs, paracetamol, chondroitin sulphate, glucosamine and COX-2 enzyme inhibitors were generally employed (MPR $=50 \%$ ) by more than $10 \%$ of the total number of users of each of these agents. This increased to more than $20 \%$ for chondroitin. Therefore combination therapies are mainstay in the management of OA.

In the study, surprisingly paracetamol prescription occupied second position after oral NSAIDS among the frequently prescribed medication of OA. Oral NSAIDS usage has been related with concerns of augmented cardiovascular risks (30\% had hypertension and $>10 \%$ had type 2 diabetes), although the usage was for short-term ${ }^{[12]}$. The recommended first-line therapy to treat OA symptoms is paracetamol ${ }^{[13,14]}$. Similarly, for the patients who are suffering from joint pain of modest to severe grade; oral NSAIDS are recommended ${ }^{[15]}$. The observations in this study are particularly relevant for OA patients, who were previously at risk for cardiovascular incidents $(>30 \%$ had hypertension and $>10 \%$ had diabetes in the data). This study is analogous to a latest Canadian study of communityliving persons aged more than 55 with knee/hip OA that exhibited those OA therapies diverse by age and gender, regardless of disease and medical and social background ${ }^{[16]}$.

Various trends in the employment of drugs in treating OA were exhibited in this study. The most common medications (paracetamol and NSAIDS) reduced gradually with time and only 3 medications usage was increased during the study tenure, which were, opioids, chondroitin and COX-2 enzyme inhibitors.
There were no particular straight forward explanations for these findings. However, probable reasons might be ageing and obesity, which were linked with augmented vulnerability towards cardiac arrest and bleeding might explain the findings ${ }^{[17]}$. Opioids prescriptions were more in OA patients who were having comorbid conditions, which might be due to decrease in the safety concerns. However, this practice could be a false belief, because opioids usage has been linked with an augmented risk of various adverse events as compared to oral NSAIDS in older patients suffering from OA symptoms, comprised of all-cause hospitalization, cardiovascular incidents and a more than higher risk (4-fold) of fractures ${ }^{[18]}$. It is clinically sensible, as a latest multi-national study reported that OA patients exhibited augmented vulnerability to falls and fractures ${ }^{[19]}$. Moreover, the yearly occurrence of new drug users of COX-2 enzyme inhibitors was anticipated to reduce gradually, but rates continuously rose in the last two years of this study ${ }^{[20,21]}$.

Findings of this study can demonstrate that only chondroitin and topical NSAIDS were frequently used (50\%) by a minimum $20 \%$ of the users of these medications, while the proportions of regular users endured between 10 and $20 \%$ for most of the general medications, including oral NSAIDS, paracetamol and COX-2 enzyme inhibitors. Usage of opioids has been particularly very low, including both tramadol (weaker) and fentanyl (stronger), which was in harmony with the recommendations. The efficacy and safety of therapeutic agents in randomized trials should be considered cautiously for medical interventions. Because usage in the actual practice conditions appeared much lower than in experimental clinical evidences. According to the ORSI (Osteoarthritis Research Society International) recommendations, opioids usage to be very restricted in time and surgical modality must be chosen for OA patients ${ }^{[20]}$. Moreover, it is suggested that non-tramadol opioids must rarely be used, even if OA pain is high ${ }^{[22]}$. Negligible use of metamizole indicated that this drug was used as a rescue medicine for flareup of symptoms. The present study, warrants a well-designed similar type of real-life setting studies with a large pool of patient population to derive valuable medical solutions. The present study, being with a large population it is first of its kind in this geography of China. Authors anticipate more of similar studies, addressing several other aspects of healthcare issues.

In summary, this study revealed that the use of various drugs for OA differed with the patient characteristic 
features. Opioids, COX-2 enzyme inhibitors and NSAIDs were extensively prescribed in elderly OA patients, which in turn could cause adverse events such as cardiovascular and fractures. The usage was very low in terms of quantity; therefore it is hard to interpret these results from clinical studies into actual practice for imparting efficacy and safety. Moreover, combined therapies were very frequent in OA patients and further data required for understanding the potential drug interactions. Findings of this study created awareness among clinicians to the potential cost implications and drug-induced side effects (iatrogenic) in the treatment of OA patients.

\section{Acknowledgements:}

This project was funded by the Wendeng Hospital of Traditional Chinese Orthopedics and Traumatology of Shandong Province. The authors, therefore, acknowledge with thank the Institution for technical and financial support.

\section{Conflicts of interest:}

The authors declare that there is no conflict of interest.

\section{REFERENCES}

1. Woolf AD, Pfleger B. Burden of major musculoskeletal condition. Bull World Health Organ 2003;81(9):646-56.

2. Murray CJ, Vos T, Lozano R, Naghavi M, Flaxman AD, Michaud C, et al. Disability-adjusted life years (DALYs) for 291 diseases and injuries in 21 regions: 1990-2010: a systematic analysis for the Global Burden of Disease Study 2010. Lancet 2012;380:2197-223.

3. Tang X, Wang S, Zhan S, Niu J, Tao K, Zhang Y, et al. The Prevalence of Symptomatic Knee Osteoarthritis in China: Results From the China Health and Retirement Longitudinal Study. Arthritis Rheumatol 2016;68:648-53.

4. Yoshimura N, Muraki S, Oka H, Tanaka S, Kawaguchi H, Nakamura K, et al. Accumulation of metabolic risk factors such as overweight, hypertension, dyslipidaemia, and impaired glucose tolerance raises the risk of occurrence and progression of knee osteoarthritis: a 3-year follow-up of the ROAD Study. Osteoarthritis Cartilage 2012;20:1217-26.

5. Nuesch E, Dieppe P, Reichenbach S, Williams S, Iff S, Jüni P. All cause and disease specific mortality in patients with knee or hip osteoarthritis: population based Cohort Study. BMJ 2011;342:d1165.

6. njrcentre.org.uk [Internet].National Joint Registry for England and Wales. 9th Annual Report 2012.; [Updated 2012. cited 2018 Jul 9] Available from: http://www.njrcentre.org.uk/ njrcentre/Portals/0/Documents/England/Reports/9th_annual_ report/NJR\%209th\%20Annual\%20Report\%202012.pdf.

7. Jordan KM, Sawyer S, Coakley P, Smith HE, Cooper C, Arden NK. The use of conventional and complementary treatments for knee osteoarthritis in the community. Rheumatology
2004;43:381-4.

8. Garcia-Gil Mdel M, Hermosilla E, Prieto-Alhambra D, Fina F, Rosell M, Ramos R, et al. Construction and validation of a scoring system for the selection of high-quality data in a Spanish population primary care database (SIDIAP). Inform Prim Care 2011;19(3):135-45.

9. Prieto-Alhambra D, Judge A, Javaid MK, Cooper C, DiezPerez A, Arden NK. Incidence and risk factors for clinically diagnosed knee, hip and hand osteoarthritis: influences of age, gender and osteoarthritis affecting other joints. Ann Rheum Dis 2014;73:1659-64.

10. who.int [Internet]. The Anatomical Therapeutic Chemical Classification System with Defined Daily Doses (ATC/DDD). [Updated 2017. cited 2018 Jul 10] Available from: http:// www.who.int/classifications/atcddd/en/.

11. Sikka R, Xia F, Aubert RE. Estimating medication persistency using administrative claims data. Am J Manag Care 2005;11:449-57.

12. McGettigan P, Henry D. Cardiovascular risk with nonsteroidal anti-inflammatory drugs: systematic review of populationbased controlled observational studies. PLoS Med 2011;8:e1001098.

13. Hochberg MC, Altman RD, April KT, Benkhalti M, Guyatt $\mathrm{G}$, McGowan J, et al. American College of Rheumatology 2012 recommendations for the use of nonpharmacologic and pharmacologic therapies in osteoarthritis of the hand, hip, and knee. Arthritis Care Res 2012;64:455-74.

14. Jordan KM, Arden NK, Doherty M, Bannwarth B, Bijlsma JW, Dieppe $\mathrm{P}$, et al. EULAR recommendations 2003: an evidence based approach to the management of knee osteoarthritis: report of a task force of the standing Committee for International Clinical Studies Including Therapeutic Trials (ESCISIT). Ann Rheum Dis 2003;62:1145-55.

15. Towheed TE, Judd MJ, Hochberg MC, Wells G. Acetaminophen for osteoarthritis. Cochrane Database Syst Rev 2006;1:CD004257.

16. Fisher JE, Ballantyne PJ, Hawker GA. Older adults living with osteoarthritis: examining the relationship of age and gender to medicine use. Can J Aging 2012;31:323-33.

17. Poirier P, Giles TD, Bray GA, Hong Y, Stern JS, Pi-Sunyer FX, et al. Obesity and cardiovascular disease: pathophysiology, evaluation, and effect of weight loss: an update of the 1997 American Heart Association Scientific Statement on Obesity and Heart Disease from the Obesity Committee of the Council on Nutrition, Physical Activity, and Metabolism. Circulation 2006;113:898-918.

18. Solomon DH, Rassen JA, Glynn RJ, Lee J, Levin R, Schneeweiss S. The comparative safety of analgesics in older adults with arthritis. Arch Intern Med 2010;170:1968-76.

19. Prieto-Alhambra D, Nogues X, Javaid MK, Wyman A, Arden NK, Azagra R, et al. An increased rate of falling leads to a rise in fracture risk in postmenopausal women with self-reported osteoarthritis: a prospective multinational cohort study (GLOW). Ann Rheum Dis 2013;72:911-7.

20. Zhang W, Doherty M, Arden N, Bannwarth B, Bijlsma J, Gunther KP, et al. EULAR evidence based recommendations for the management of hip osteoarthritis: report of a task force of the EULAR Standing Committee for International Clinical 
www.ijpsonline.com

Studies Including Therapeutics (ESCISIT). Ann Rheum Dis 2005;64:669-81.

21. Zhang W, Moskowitz RW, Nuki G, Abramson S, Altman RD, Arden $\mathrm{N}$, et al. OARSI recommendations for the management of hip and knee osteoarthritis, part II: OARSI evidence- based, expert consensus guidelines. Osteoarthritis Cartilage 2008;16:137-62.

22. da Costa BR, Nuesch E, Kasteler R, Husni E, Welch V, Rutjes A, et al. Oral or transdermal opioids for osteoarthritis of the knee or hip. Cochrane Database Syst Rev 2009;4:CD00311. 